\title{
UK Renal Registry 14th Annual Report: Appendix E Methodology for Estimating Catchment Populations of Renal Centres in England for Dialysis Patients
}

\section{Introduction}

Providing accurate centre-level incidence and prevalence rates for patients receiving renal replacement therapy (RRT) in the UK was limited until the 13th Annual Report by the difficulty in estimating the catchment population from which the RRT population is derived. One reason for this is that the geographical boundaries separating renal centres are relatively arbitrary and dependent upon a number of factors including referral practice, patient choice and patient movement. Previously incidence and prevalence rates had been calculated at Local Authority/Primary Care Trust/Health Board level where denominator data were available, but not at renal centre level.

UK Renal Registry (UKRR) Annual Reports prior to the 13th suggested an estimate of the size of the catchment populations. These were extrapolated figures originally derived from data in the 1992 National Renal Survey undertaken by Paul Roderick.

The purpose of this document is to present an estimate of the dialysis catchment population for all renal centres in England. The document also contains a methodological description and discussion of the limitations of this estimate. These catchment population estimates were used in the 13th Annual Report (chapter 1: UK RRT Incidence in 2009: national and centre-specific analyses) to calculate RRT incidence rates by renal centre, rather than only by Primary Care Trust/HB. From the 14th Annual Report both incidence and

\section{KARGER}

Fax +4161306 1234 E-Mail karger@karger.ch www.karger.com
(C) 2012 S. Karger AG, Basel

$1160-2110 / 12 / 1185-0283 \$ 38.00 / 0$

Accessible online at: www.karger.com/nec prevalence rates are given by renal centre as well as by Primary Care Trust/HB.

\section{Methods}

The UK Renal Registry database of the prevalent dialysis population on 31st December 2007 was used to estimate the size of each renal centre's catchment population. This used the postcode and dialysis centre for each individual dialysis patient.

An area was drawn around the geographical location of each dialysis patient, producing an overlapping polygonal area. The shape and size of this area was based upon the location of other dialysis patients surrounding them. Using these areas for individual patients, the total catchment area for each renal centre was merged and the Office for National Statistics (ONS) census-area statistics (CAS) wards overlaid upon the renal centre catchment area. Each CAS-ward was then assigned to the corresponding renal centre. If more than one renal centre catchment area corresponded to a CAS-ward, then only a percentage of the ward was assigned to each centre, proportionate to the area covered.

The ONS publishes the number of people living in each ward, based upon the April 2001 Census. This information is available on the ONS website. We used this information to calculate the number of people living in the census ward allocated to each renal centre. If only a

UK Renal Registry, Southmead Hospital, Southmead Road Bristol, BS10 5NB, UK

Email: renalregistry@renalregistry.nhs.uk 
proportion of a ward was allocated to a centre, we attributed the same proportion of the population to that centre's denominator.

The ONS annually estimates the increase in the UK population at national and Local Authority level. When the work detailed here was being done the latest update available was to June 2008. The ONS also updates the population estimates at CAS-ward level. The latest update available at CAS-ward level was to June 2007. This information was not available on the ONS website but was provided by direct communication and permission granted to use for this analysis. It was necessary to use the ONS data at the CAS-ward level, therefore the June 2007 data were used for the latest UKRR analysis.

The allocation of catchment ward to renal centre was only undertaken for England and therefore estimated catchment populations for renal centres in Scotland, Wales and Northern Ireland have not been calculated.

This allocation exercise was performed before Colchester became a separate renal centre.

\section{Results}

The estimated dialysis catchment populations for renal centres in England are shown in Table E.1. The table shows both calculations: first from the ONS Census from April 2001 and second from the updated ONS estimates of CAS-ward populations at June 2007.

\section{Discussion}

These results show the updated estimates for the size of the catchment areas for each of the renal centres in England. This analysis was the first time that the UK Renal Registry has been able to accurately estimate the catchment population for each English centre.

There are some limitations to these results. The first is that the ward allocated to each renal centre was based upon dialysis patients only. Therefore it is possible that

Table E.1. Estimated dialysis catchment populations of English renal centres based upon firstly 2001 and secondly mid-2007 ONS CAS-ward population estimates (rounded to nearest 1,000 )

\begin{tabular}{|c|c|c|c|c|c|}
\hline Centre & 2001 estimate & Mid-2007 estimate & Centre & 2001 estimate & Mid-2007 estimate \\
\hline B Heart & 704,000 & 725,000 & Leeds & $1,574,000$ & $1,647,000$ \\
\hline B QEH & $1,585,000$ & $1,624,000$ & Leic & $2,180,000$ & $2,318,000$ \\
\hline Basldn & 396,000 & 408,000 & Liv Ain & 295,000 & 290,000 \\
\hline Bradfd & 546,000 & 579,000 & Liv RI & $1,198,000$ & $1,199,000$ \\
\hline Brightn & $1,161,000$ & $1,195,000$ & M Hope & $1,403,000$ & $1,420,000$ \\
\hline Bristol & $1,472,000$ & $1,571,000$ & M RI & $1,398,000$ & $1,469,000$ \\
\hline $\mathrm{Camb}^{\star}$ & $1,181,000$ & $1,266,000$ & Middlbr & 981,000 & $1,012,000$ \\
\hline Carlis & 307,000 & 314,000 & Newc & $1,086,000$ & $1,106,000$ \\
\hline Carsh & $1,852,000$ & $1,916,000$ & Norwch & 755,000 & 793,000 \\
\hline Chelms* & 445,000 & 466,000 & Nottm & $1,091,000$ & $1,138,000$ \\
\hline Covnt & 839,000 & 870,000 & Oxford & $1,598,000$ & $1,680,000$ \\
\hline Derby & 611,000 & 647,000 & Plymth & 456,000 & 476,000 \\
\hline $\operatorname{Donc}^{* *}$ & 210,000 & 214,000 & Ports & $1,926,000$ & $2,003,000$ \\
\hline Dorset & 710,000 & 725,000 & Prestn & $1,475,000$ & $1,512,000$ \\
\hline Dudley & 411,000 & 415,000 & Redng & 782,000 & 805,000 \\
\hline Exeter & 969,000 & $1,028,000$ & Sheff $^{\star}$ & $1,451,000$ & $1,489,000$ \\
\hline Glouc & 558,000 & 575,000 & Shrew & 382,000 & 391,000 \\
\hline Hull & 945,000 & 987,000 & Stevng & $1,047,000$ & $1,088,000$ \\
\hline Ipswi* & 523,000 & 562,000 & Sthend & 309,000 & 316,000 \\
\hline Kent & $1,112,000$ & $1,163,000$ & Stoke & 880,000 & 897,000 \\
\hline L Barts & $1,608,000$ & $1,680,000$ & Sund & 585,000 & 589,000 \\
\hline L Guys & $1,102,000$ & $1,154,000$ & Truro & 390,000 & 412,000 \\
\hline L Kings & 932,000 & 970,000 & Wirral & 520,000 & 521,000 \\
\hline L Rfree & $1,412,000$ & $1,504,000$ & Wolve & 606,000 & 606,000 \\
\hline L St G & 553,000 & 585,000 & York & 478,000 & 505,000 \\
\hline L West & $2,113,000$ & $2,227,000$ & England & $49,104,000$ & $51,050,000$ \\
\hline
\end{tabular}

${ }^{*}$ some reduction required after the opening of Colchester renal centre and the expansion of Doncaster

${ }^{* *}$ population may be too low as centre has expanded 
non-dialysis patients may come from a different catchment population. This is more likely where a renal centre provides specialist services and especially likely for patients undergoing renal transplantation. The catchment population for renal transplant patients will depend largely upon the distribution of workload between the referral centre and the transplanting centre for pre-transplant work-up, donor nephrectomy workup and post-transplant care (including if and when care is returned to the referring centre).

These estimates were performed before Colchester became a separate renal centre. Therefore it is likely that the catchment populations of the neighbouring renal centres; Chelmsford, Ipswich, Cambridge, are somewhat too high. It is thought that the catchment population of Colchester may be in the region of 200,000 people.

Despite these limitations, this is the most valid methodology to date to estimate the size of the catchment populations for renal centres in England.
The results of this analysis allow the UKRR to calculate estimates of the incidence and prevalence rates of renal replacement therapy at renal centre level, rather than only at PCT/HB level.

These results also provide other opportunities for study of the catchment populations. The ONS provides data on gender, age and ethnicity of the population at ward level. It should be possible to use this information to consider centre differences in the demographics of patients commencing or receiving RRT with adjustment for the catchment population characteristics.

\section{Acknowledgements}

This is primarily the work of Andrew Judge.

Others who helped include (listed alphabetically): David Ansell, Yoav Ben-Shlomo, Daniel Ford, Paul Roderick, Charles R V Tomson. 